\title{
Cytokines and Troponin-I in Cardiac Dysfunction After Coronary Artery Grafting with Cardiopulmonary Bypass
}

\author{
Neverton Savaris, Carisi Polanczyk, Nadine Clausell \\ Porto Alegre, RS - Brazil
}

\begin{abstract}
Objective - The association between cytokines and troponin-I with cardiac function after cardiac surgery with cardiopulmonary bypass remains a topic of continued investigation.
\end{abstract}

Methods - Serial measurements, within 24 following surgery, of tumor necrosis factor- $\alpha$, its soluble receptors, and troponin-I were performed in patients with normal ejection fraction undergoing coronary artery bypass grafting. Ejection fraction was measured by radioisotopic ventriculography preoperatively, at $24 \mathrm{~h}$ and at day 7 postoperatively.

Results - Of 19 patients studied (59 \pm 8.5 years), 10 (group 1) showed no changes in ejection fraction, $53 \pm 8 \%$ to $55 \pm 7 \%$, and 9 (group 2) had a decrease in ejection fraction, $60 \pm 11 \%$ to $47 \pm 11 \%(p=0.015)$ before and $24 \mathrm{~h}$ after coronary artery bypass grafting, respectively. All immunological variables, except tumor necrosis factor- $\alpha$ soluble receptor I at 3 h postoperation (5.5 0.5 in group 1 versus $5.9 \pm 0.2 \mathrm{pg} / \mathrm{ml}$ in group $2 ; \mathrm{p}=0.048$ ), were similar between groups. Postoperative troponin-I had an inverse correlation with ejection fraction at $24 \mathrm{~h}(r=-0.44)$.

Conclusions - Inflammatory activity, assessed based on tumor necrosis factor- $\alpha$ and its receptors, appears to play a minor role in cardiac dysfunction after cardiac surgery. Troponin I levels are inversely associated with early postoperative ejection fraction.

Key words: cytokines, troponin-I, myocardial function, inflammatory response

Hospital de Clínicas de Porto Alegre - Federal University of Rio Grande do Sul Mailing Address: Nadine Clausell - Hospital de Clínicas de Porto Alegre - Rua Ramiro Barcelos, 2350 - room 2059 - 90035-003 - Porto Alegre, SP - Brazil - email: clausell@portoweb.com.br
Although outcomes from cardiac surgery have improved significantly over the last few years, myocardial dysfunction remains a common problem after cardiopulmonary bypass ${ }^{1}$. Cardiopulmonary bypass activates a proinflammatory cascade, releasing several inflammatory mediators that may be in part associated with the development of left ventricular dysfunction following cardiac surgery, also known as post-perfusion syndrome ${ }^{2-5}$.

Inflammatory mediators identified in postcardiopulmonary bypass syndrome, include tumor necrosis factor (TNF)- $\alpha$ and interleukins (IL)-1, 2, 6, 8 and 10 2,3 . The timecourse of the release of these markers in this setting, especially TNF- $\alpha$, remains controversial, perhaps due to different assays used and to different study protocols ${ }^{2,3}$. In addition, TNF- $\alpha$ is thought to be influenced by its soluble receptors (sr) I and II; thus. additional studies including these may help to further clarify this question ${ }^{6}$.

Cytokines have been associated with depressed myocardial function to different conditions such as heart failure and sepsis ${ }^{7,8}$. It is considered that TNF- $\alpha$ may lead to increased nitric oxide production that in turn may, through inhibition of $\beta_{1}$-receptors in myocytes, cause reduced contractility ${ }^{9,10}$. Additionally, because TNF- $\alpha$ may be related to myocyte damage, it is possible that myocardial dysfunction associated with cytokine release could in turn be related to cell injury ${ }^{10}$.

Troponin (Tn)-I is a myocyte-contractile apparatus protein released following myocyte damage. Levels of Tn-I are considered sensitive markers of myocardial infarct associated or not with cardiac surgery ${ }^{11,12}$. However, it is unknown whether the Tn-I release pattern is temporally related to myocardial dysfunction after coronary artery bypass grafting with cardiopulmonary bypass.

The objective of this study was to describe the temporal pattern of TNF- $\alpha$, its soluble receptors I and II, and Tn-I in patients undergoing coronary artery bypass grafting with cardiopulmonary bypass who have preserved myocardial function prior to surgery. In addition, these markers 
were correlated with serial measures of left ventricular function postoperatively.

\section{Methods}

Patients undergoing coronary artery bypass grafting with cardiopulmonary bypass at the Hospital de Clínicas de Porto Alegre (a tertiary care center) from February 1997 to January 1998 were considered for enrollment in this study. Patients were excluded if cardiopulmonary bypass was previously used, acute myocardial infarction had occurred within 3 months, or the need existed for simultaneous cardiac surgery procedure (valvar replacement, repair of congenital heart defects). In addition, patients with chronic renal failure, acquired immunodeficiency syndrome, infectious disease status, unstable angina, heart failure NYHA class III or IV, in use of steroids chronically or perioperatively, with ejection fraction $<40 \%$ were also not included. Exclusion criteria in the postoperative period were: perioperative myocardial infarction (according to standard criteria), systolic blood pressure $<80 \mathrm{mmHg}$, low cardiac output signs with oligo-anuria or impaired tissue perfusion or cardiac arrhythmias requiring electric cardioversion within $24 \mathrm{~h}$ postoperation. This study was approved by the Ethics and Research Committee of Hospital de Clínicas de Porto Alegre, and prior to enrollment patients signed an informed consent to participate.

Patients were prepared according to standard procedures. General anesthesia was carried out using a balanced anesthetic technique with midazolam, fentanyl, and pancuronium intravenously, and maintenance of anesthesia was performed using isoflurane with $50 \%$ oxygen. Monitoring included: continuous electrocardiogram, pulse oximetry, invasive mean arterial pressure, central venous pressure (HewlettPackard, model 66S, Waltham, MA, USA), and rectal and nasopharyngeal temperature by electronic thermometers. The cardiopulmonary bypass system was constituted of an arterial roller pump (Macchi Model 5, São Paulo, SP, Brazil) and an extracorporeal circuit mounted with membrane oxygenator (Braile Biomédica, São José do Rio Preto, SP, Brazil). Arrest was maintained with intermittent antegrade crystalloid cold $\left(4^{\circ} \mathrm{C}\right)$ cardioplegic St Thomas II solution (B Braun solution, São Gonçalo, RJ, Brazil) given every $20 \mathrm{~min}$. Body temperature was maintained between 28 and $32^{\circ} \mathrm{C}$. Coronary artery bypass grafting was performed following standard protocols ${ }^{5}$. Vasodilators were used as part of routine postsurgical care that was carried out without interference of the study protocol.

Left ventricular ejection fraction was evaluated preoperatively, at $24 \mathrm{~h}$ postcardiopulmonary bypass, and at day seven postoperation with rest radioisotopic ventriculography. Red cells were labeled with Tc-99m pyrophosphate and images were acquired in the left anterior oblique projection at $30^{\circ} \mathrm{C}$ with a 1.6 zoom using $25-30 \mathrm{mci}$ in a gamma camera with automatic software processing (General Electric Company Starcam 400i, Milwaukee, Wisconsin, USA). An independent observer unaware of patient status or other laboratory data performed the analysis of ventriculography data.

Fifteen milliliters of arterial blood samples were drawninto tubes containing ethylenediaminetetraacetic acid and $5 \mathrm{~mL}$ of blood in tubes without anticoagulation for posterior determination of TNF- $\alpha$, srITNF- $\alpha$, srIITNF- $\alpha$, and Tn-I, respectively, attimezero (T0) (anesthesia induction), T3, T8, and T24 (3, 8, and 24h after initiation of cardiopulmonary bypass, respectively). Samples were immediately cold-centrifuged at $2000 \mathrm{rpm}$ for $20 \mathrm{~min}$, and plasma andserum werestored at $-70^{\circ} \mathrm{C}$ forposterior simultaneousenzymelinked immunoabsorbent assay (ELISA) assessment of markers with commercially availablekits (TNF- $\alpha$ and its soluble receptors -R\& Systems, Minneapolis, MN,USA) and Tn-I(Opus Behring Diagnostics Inc, Westwood, MA, USA). Sensitivity and range values for normal control individuals expected according to the manufacturerwere: TNF- $\alpha$-fromnondetectable up to $4.12 \mathrm{pg} / \mathrm{mL}$, srITNF-from 484to $1407 \mathrm{pg} / \mathrm{mL}$, srIITNF-from 829 to $2262 \mathrm{pg} / \mathrm{mL}$, and Tn-I-less than $0.5 \mathrm{ng} / \mathrm{mL}$.

Data were analyzed with commercially available software (SPSS). Continuous variables with normal distribution are presented as means \pm standard error or standard deviation where appropriate. Data with nonparametric distribution were log transformed. Patients were divided into 2 groups according to ejection fraction at $24 \mathrm{~h}$ postoperation: group 1 - unchanged ejection fraction and group 2 - decreased ejection fraction. The Student $t$ test or Fisher's exact test was used to compare clinical characteristics between groups. Analysis of variance for repeated measures (MANOVA) was used to analyze biological markers and ejection fraction in different time points within groups and between groups. Spearman correlation coefficient was used to study associations between clinical and laboratory variables. The level of significance was established at $\mathrm{p}<0.05$.

\section{Results}

Nineteen patients were enrolled in the study. No cardiac events occurred in any of the patients studied, and all received dopamine $5 \mathrm{mg} / \mathrm{kg} / \mathrm{min}$ after withdrawal from cardiopulmonary bypass until termination of the surgery. No patient needed inotropic support in the postoperative period. Routine postoperative care included use of intravenous sodium nitroprusside as needed and mechanical ventilation until extubation that occurred usually within 8 to $12 \mathrm{~h}$ postoperatively. Clinical characteristics of the patients are presented in table I.

At the time of left ventricular function assessment, patients were extubated, hemodynamically stable without inotropic support or use of vasodilators. Left ventricular ejection fraction was unchanged at $24 \mathrm{~h}$ and 7 days postoperatively compared with baseline in 10 patients (group 1). However, in 9 patients (group 2) a significant decrease occurred in the ejection fraction at $24 \mathrm{~h}$ followed by almost full recovery at day 7 compared to with baseline (fig. 1).

TNF- $\alpha$ plasma levels varied significantly in all patients studied in all time-points analyzed, with peak values at $3 \mathrm{~h}$ after cardiopulmonary bypass initiation. The temporal 


\begin{tabular}{|c|c|c|c|}
\hline \multicolumn{4}{|c|}{ Table I - Perioperative variables } \\
\hline Variable & $\begin{array}{l}\text { Group 1 } \\
(\mathrm{n}=10)\end{array}$ & $\begin{array}{l}\text { Group } 2 \\
(\mathrm{n}=9)\end{array}$ & $\mathrm{P}$ \\
\hline Age (years) * & $58 \pm 7.8$ & $59 \pm 9.2$ & NS \\
\hline Weight $(\mathrm{kg})^{*}$ & $81.6 \pm 14.3$ & $71.1 \pm 19.3$ & NS \\
\hline $\operatorname{Sex}(M / F)$ & 9/1 & $6 / 3$ & NS \\
\hline Number of grafts* & $2.8 \pm 0.9$ & $2.6 \pm 0.5$ & NS \\
\hline Mammary arteries used & $6(60 \%)$ & $5(55.6 \%)$ & NS \\
\hline Bypass time (minutes)* & $66.1 \pm 21.7$ & $61.1 \pm 18.2$ & NS \\
\hline $\begin{array}{l}\text { Cross-clamp } \\
\text { time (minutes)* }\end{array}$ & $45.9 \pm 20.1$ & $38.3 \pm 15.7$ & NS \\
\hline \multicolumn{4}{|c|}{$\begin{array}{l}* \text { Variables are given as mean } \pm \mathrm{SD} \text {; group } 1 \text { refers to patients with } \\
\text { unchanged ejection fraction after surgery; group } 2 \text { refers to patients with } \\
\text { decreased ejection fraction after surgery. M denotes male; F denotes } \\
\text { female; NS- not significant ( } \mathrm{p} \geq 0.05 \text { ). }\end{array}$} \\
\hline
\end{tabular}

profile for both srITNF and srIITNF was similar to that of TNF- $\alpha$. For the 3 markers, levels remained above baseline values up to the $24 \mathrm{~h}$ time-point. Similar results were observed for Tn-I because all patients had significantly increased levels in all time-points with peak values observed $24 \mathrm{~h}$ after starting cardiopulmonary bypass (table II).

A trend towards higher plasma levels of TNF- $\alpha$ at $3 \mathrm{~h}$ was observed in patients who had significantly lower ejection fraction postoperatively compared with patients who had unchanged ejection fraction after surgery (log

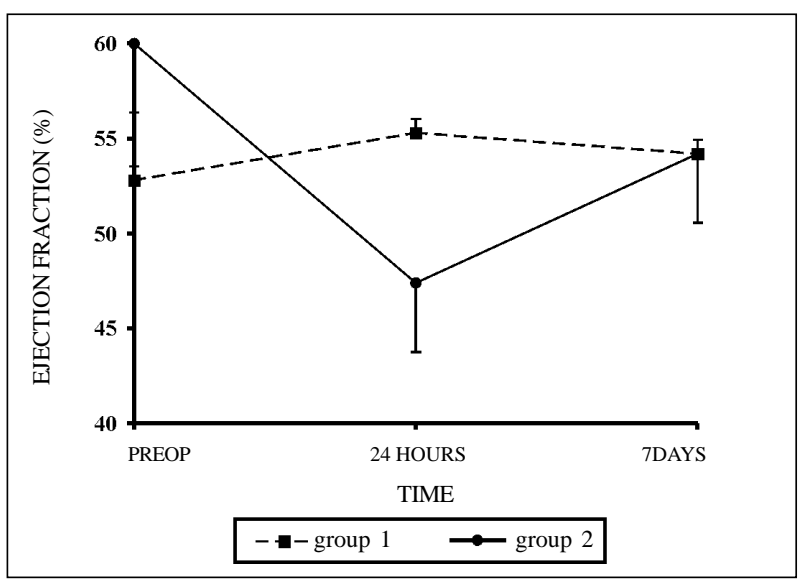

Fig. 1- Baseline, 24 hour and day 7 postoperative values of ejection fraction as assessed by radioisotopic ventriculography in groups 1 and 2 . Values are given as mean \pm SEM. $* \mathrm{p}=0.015$ refers to comparison between baseline and 24 hours postoperation.
$3.11 \pm 0.15 \mathrm{pg} / \mathrm{mL}$ versus $\log 2.56 \pm 0.23 \mathrm{pg} / \mathrm{mL} ; \mathrm{p}=0.07$ ) (fig. 2A). Profiles of srIITNF and Tn-I did not differ between the two groups of patients in any of the time-points analyzed, whereas srITNF at $3 \mathrm{~h}$ had significantly higher values in patients with decreased ejection fraction (Figure 2B, C and D). However, levels of $\mathrm{Tn}-\mathrm{I}$ at $8 \mathrm{~h}$ after cardiopulmonary bypass showed an inverse correlation with ejection fraction measured at $24 \mathrm{~h}$ for all patients, irrespective of individual groups $(\mathrm{r}=-0.44 ; \mathrm{p}=0.06)$.

In all patients, baseline Tn-I levels were within the normal range $(<0.05 \mathrm{pg} / \mathrm{mL})$, and in all a serial increase occurred in subsequent measurements, although without meeting criteria for perioperative myocardial infarct ${ }^{13}$. Troponin I plasma levels measured at $8 \mathrm{~h}$ and $24 \mathrm{~h}$ cardiopulmonary bypass start correlated positively with duration of cardiopulmonary after bypass and aortic clamping duration (figs. 3 A, B, C, D).

\section{Discussion}

Cardiopulmonary bypass is associated with immunoinflammatory activation and different levels of cardiac injury, which can be identified by increased cytokine and troponin levels, respectively. Moreover, cardiac dysfunction is common in patients who undergo coronary artery bypass grafting with cardiopulmonary bypass. In this study, patients with preserved cardiac function undergoing myocardial revascularization were studied to evaluate left ventricular function, and cytokine and troponin levels, serially in the postoperative period.

Several studies have demonstrated left ventricular dysfunction following cardiac surgery with cardiopulmonary bypass ${ }^{1}$. In patients with preserved cardiac function, it usually occurs 2 to $6 \mathrm{~h}$ after surgery and may recover almost completely within $4 \mathrm{~h}^{1}$. In our study, according to left ventricular values obtained at $24 \mathrm{~h}$ postoperation, patients were divided into 2 groups: patients with normal and with decreased ejection fraction compared to baseline. Both groups were similar regarding all other variables, such as cardiopulmonary bypass duration and aortic clamping time. In prior studies, these 2 factors have been associated with cardiopulmonary bypass-induced inflammatory activation and degree of myocardial dysfunction following cardiopulmonary bypass ${ }^{4,5}$. Almost half of patients in the present study had reduced ejection fraction at 24 compared with

\begin{tabular}{|c|c|c|c|c|c|}
\hline \multicolumn{6}{|c|}{ Table II - Plasma levels of biological markers in different time-points } \\
\hline Markers & T0 & $\mathrm{T} 3$ & $\mathrm{~T} 8$ & $\mathrm{~T} 24$ & $\mathrm{P}$ \\
\hline $\log$ TNF- $\alpha(\mathrm{pg} / \mathrm{ml})$ & $1.57 \pm 0.11$ & $2.83 \pm 0.15$ & $2.37 \pm 0.18$ & $2.28 \pm 0.11$ & $<0.05$ \\
\hline $\log \operatorname{srITNF}(\mathrm{pg} / \mathrm{ml})$ & $4.54 \pm 0.09$ & $5.71 \pm 0.10$ & $5.51 \pm 0.11$ & $5.45 \pm 0.09$ & $<0.05$ \\
\hline $\log \operatorname{srIITNF}(\mathrm{pg} / \mathrm{ml})$ & $5.98 \pm 0.08$ & $6.46 \pm 0.11$ & $6.47 \pm 0.12$ & $6.57 \pm 0.10$ & $<0.05$ \\
\hline Tn-I (ng/ml) & $<0.5$ & $3.66 \pm 0.57$ & $13.31 \pm 2.20$ & $21.87 \pm 6.94$ & $<0.05$ \\
\hline $\begin{array}{l}\text { TNF- } \alpha \text { : tumor necros } \\
\text { I; Time-points: T0: af } \\
\text { and its receptors and }\end{array}$ & $\begin{array}{l}\text { TNF- } \alpha \text { : solub } \\
\text { c induction, T } \\
\text { Tn-I. }\end{array}$ & $\begin{array}{l}\text { factor alpha } \\
24 \text { hours afte }\end{array}$ & f cardiopulm & $\begin{array}{l}\text { is factor alph } \\
\text { Values are ex }\end{array}$ & $\begin{array}{l}\text { : troponin } \\
\mathrm{am} \text { for } \mathrm{TN}\end{array}$ \\
\hline
\end{tabular}



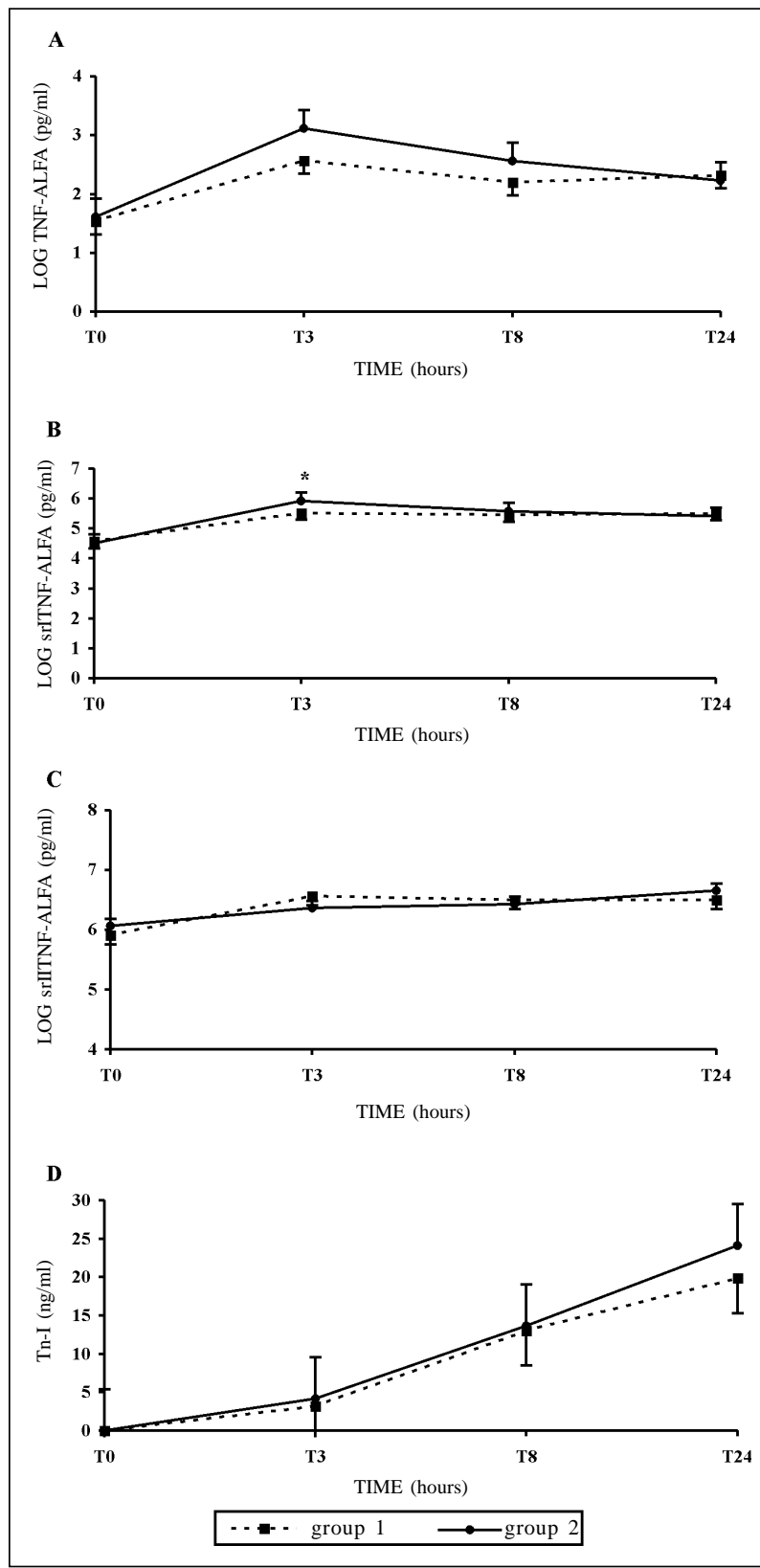

Fig. 2 - Comparison of plasma levels of TNF- $\alpha$ (A), srITNF- $\alpha$ (B) and srIITNF- $\alpha$ (C) and of serum levels of Tn-I(D) between groups. Time-points: T0: after anesthetic induction; T3, T8, T24: 3, 8 and 24 hours after the beginning of cardiopulmonary bypass.

$* \mathrm{p}=0.048$ group 1 versus 2 in T3 (figure 2B). TNF- $\alpha$ : tumor necrosis factor, srITNF- $\alpha$ : soluble tumor necrosis factor alpha receptor I, srIITNF- $\alpha$ : soluble tumor necrosis factor alpha receptor II, Tn-I: troponin-I.

baseline. It is possible that additional patients could also have had depressed cardiac function, had the evaluation been carried out earlier, ie, 2 to $4 \mathrm{~h}$ following surgery, which is considered the timing of highest cardiac dysfunction. Nonetheless, we may speculate that patients experiencing left ventricular dysfunction at $24 \mathrm{~h}$ could have a more pronounced and persistent compromise in cardiac function.

Cytokine profile - Tumor necrosis factor- $\alpha$ is a wellknown inflammatory mediator with multiple cardiovascular effects, including hypotension and depressed myocardial function. Its profile in cardiac surgery with cardiopulmonary bypass and its role in cardiac dysfunction following cardiopulmonary bypass remains controversial. Different studies have attempted to address this issue, but disparities in clinical conditions and in study designs make results difficult to interpret ${ }^{2,3}$. In this study, highly sensitive commercial kits for TNF- $\alpha$ detection were used, and a significant increase in TNF- $\alpha$ was observed in all time-points following cardiopulmonary bypass start, with peak values at $3 \mathrm{~h}$. These observations confirm the results from others that demonstrated increased TNF-a levels after cardiac surgery, reinforcing the concept that immunoinflammatory activation induced by cardiopulmonary bypass occurs ${ }^{4}$.

Although TNF- $\alpha$ is a well-described cytokine, recently, much interest has emerged from studying its cellular receptors. Indeed, TNF- $\alpha$ exerts its actions through 2 membrane-bound receptors (srI and srII) that are cleaved from the cell surface after TNF- $\alpha$ action has taken place ${ }^{14}$. After being released from the cell surface, these receptors may act both as blockers of TNF- $\alpha$ activity by binding to it in the circulation or stabilizing it forming a homodimer compound that could serve as a reservoir for later TNF- $\alpha$ activity ${ }^{14}$. Elevated levels of soluble receptors of TNF- $\alpha$ have been described in different clinical conditions, including heart failure and sepsis ${ }^{7,15}$. We have recently demonstrated that increased srITNF levels were associated with higher mortality in septic shock ${ }^{15}$. Few studies, however, have investigated the profile of TNF- $\alpha$ soluble receptors in cardiac surgery with cardiopulmonary bypass ${ }^{2}$. In this study, we demonstrate that both srI and srIITNF had a similar behavior to TNF- $\alpha$, with peak values at $3 \mathrm{~h}$ and progressive decay at $24 \mathrm{~h}$.

Several studies have suggested that cytokines could be associated with left ventricular dysfunction following coronary bypass with cardiopulmonary bypass; however, it remains unclear in which manner and whether these observations are cause related ${ }^{4,5}$. It has been shown experimentally that cytokines can induce nitric oxide synthase that will modulate myocyte response to muscarinic and beta-adrenergic receptors leading to decreased contractility secondary to adrenergic stimuli ${ }^{9}$.

In this study, we could not demonstrate significant associations between cytokine levels and cardiac dysfunction, as only levels of srITNF at its peak value were significantly higher in patients who developed left ventricular dysfunction. Thus, although from our data some degree of cardiac dysfunction could be related to inflammatory activity, other mechanisms ought to be involved.

Troponin I levels - Studies on troponins, markers of cardiac injury, have been helpful to in identifying risk conditions in different clinical settings and to determine the prognosis after cardiac events ${ }^{16,17}$. In cardiac surgery, Tn-I has been used to identify perioperative myocardial infarction, but little is known about whether it relates to cardiac dysfunction postoperatively ${ }^{18,19}$. Others have shown that Tn-I levels following cardiac surgery for congenital repairs were associated with the need for inotropic support, cardiopulmonary bypass and aortic clamping duration, and a stay in intensive care unit ${ }^{20}$. 


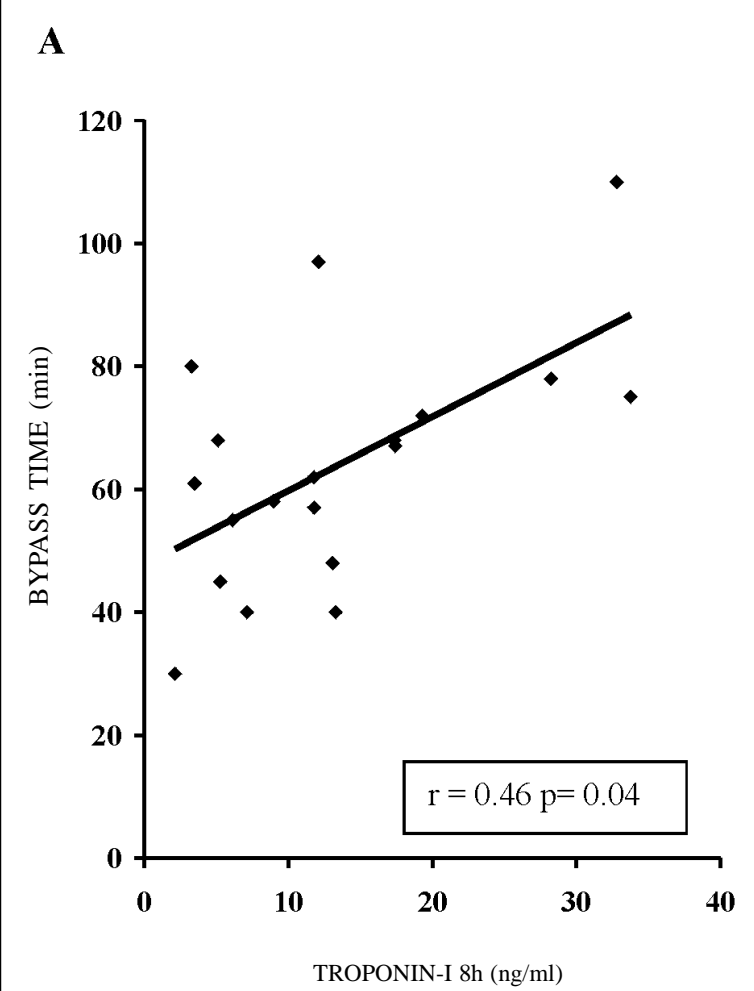

C

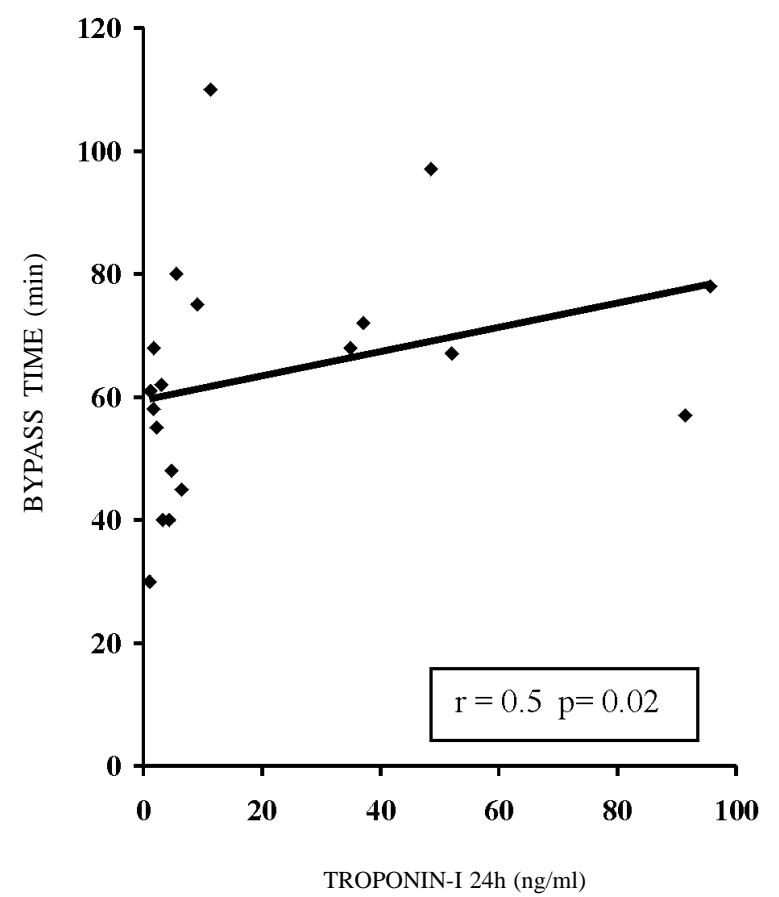

B

D
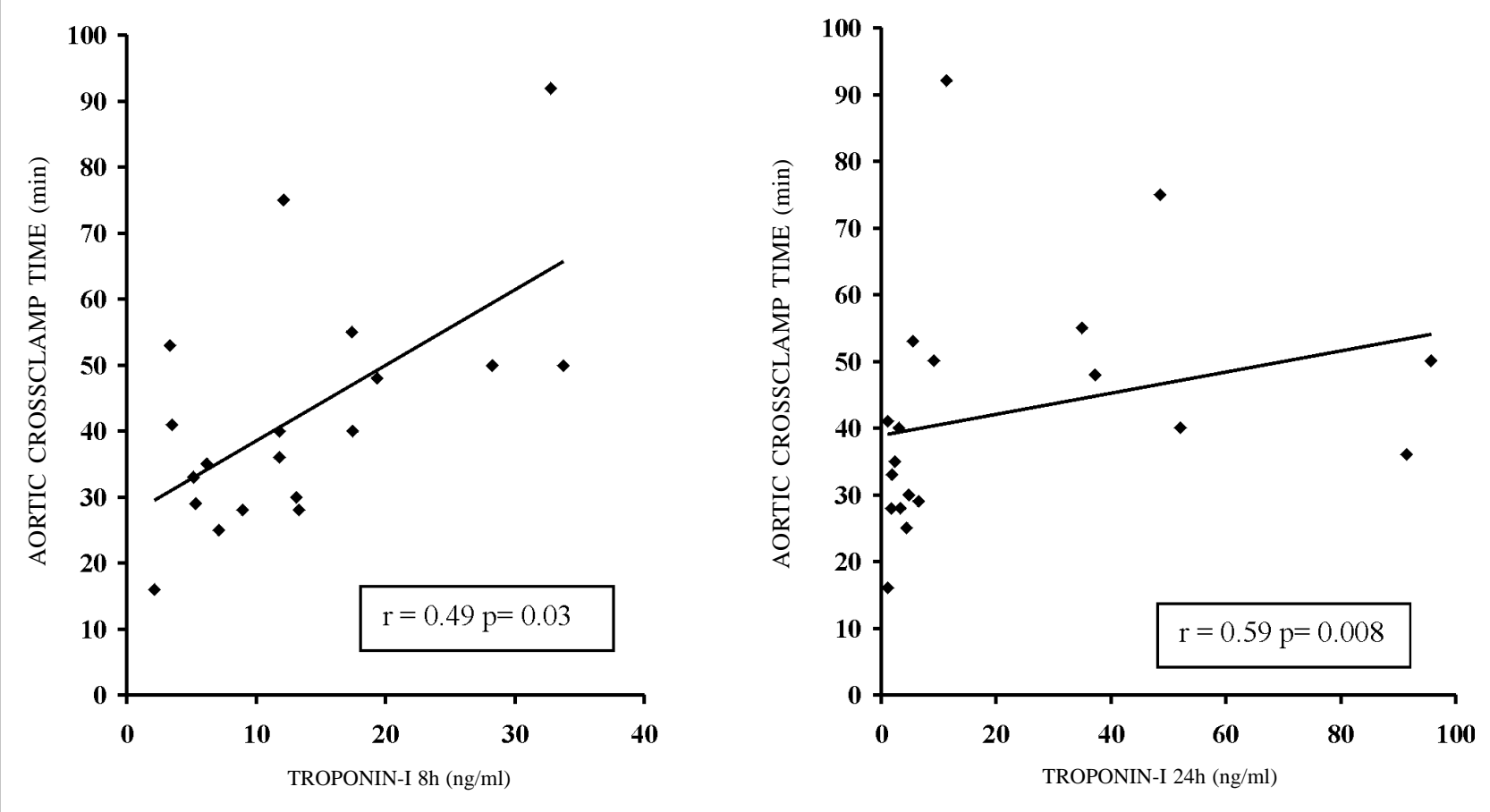

Fig. 3 - Correlation between serum levels of Tn-I at 8 and 24 hours with cardiopulmonary bypass duration (A, C) and with aortic cross-clamp duration (B, D), respectively. $r=$ Spearman's correlation coefficient; Tn-I: troponin-I.

In the present study, we demonstrate that, compared with baseline values, increased Tn-I levels occurred in all patients subsequently up to $24 \mathrm{~h}$ following surgery with peak values in $24 \mathrm{~h}$. Although Tn-I values did not correlate with TNF- $\alpha$ and TNF- $\alpha$ soluble receptor levels, it positively correlated with cardiopulmonary bypass duration and aortic clamping time, and showed an inverse correlation with left ventricular function. Our data imply that in addition to 
inflammatory activity, some degree of cardiac injury may contribute to left ventricular dysfunction after cardiac surgery with cardiopulmonary bypass.

Study limitations - Results of this study should be viewed considering potential study limitations. These observations were made in a very low-risk patient population, ie, patients with preserved left ventricular ejection fraction prior to surgery and with no complications afterwards. It could be speculated that in the presence of initial cardiac dysfunction, the role of cytokines could be more evident in further jeopardizing cardiac performance. Also, by performing the first postoperative cardiac function assessment only $24 \mathrm{~h}$ following surgery, additional cases of cardiac dysfunction may have been missed; however, by doing so, possibly more severe and persistent presentations were studied. Finally, the study objective was to determine associations between cytokines and Tn-I with left ventricular ejection fraction following cardiac surgery with cardiopulmonary bypass; thus, cause and effect assumptions cannot be made.

\section{Conclusion}

These observations demonstrate serial elevations of circulating levels of TNFN- $\alpha$, srI, and srIITNF, and Tn-I in low-risk patients who underwent coronary bypass grafting with cardiopulmonary bypass. Except for srITNF peak levels at $3 \mathrm{~h}$, no association was found between cytokine profile and left ventricular function postoperatively. Tn-I profile, however, showed more significant associations with both cardiopulmonary bypass and aortic clamping duration and with left ventricular dysfunction. Taken together these data suggest that both inflammatory activity and cardiac injury contribute to the development of cardiac dysfunction following cardiac surgery with cardiopulmonary bypass.

\section{Acknowledgments}

We wish to thank the cardiovascular surgical team (Drs. Gilberto V. Barbosa, Jair Saadi, Eduardo Saadi, and Orlando Wender) from Hospital de Clínicas de Porto Alegre for allowing the use of data obtained from patients under their surgical care. We also thank medical students Luciana Dei Ricardi and Raquel Goldhart for helping with data collection.

\section{References}

1. Mangano DT. Biventricular function after myocardial revascularization in humans: deterioration and recovery patterns during the first 24 hours. Anesthesiology 1985; 62: 571-7.

2. Hall RI, Smith MS, Rocker G. The systemic inflammatory response to cardiopulmonary bypass: pathophysiological, therapeutic, and pharmacological considerations. Anesth Analg 1997; 85: 766-82.

3. Menasché $P$. The inflammatory response to cardiopulmonary bypass and its impact on postoperative myocardial function. Curr Opin Cardiol 1995; 10: 597-604.

4. Deng MC, Dasch B, Erren M, et al. Impact of left ventricular dysfunction on cytokines, hemodynamics, and outcome in bypass grafting. Ann Thorac Surg 1996; 62: 184-90.

5. Hennein HA, Ebba H, Rodriguez JL, et al. Relationship of the proinflammatory cytokines to myocardial ischemia and dysfunction after uncomplicated coronary revascularization. J Thorac Cardiovasc Surg 1994; 108: 626-35.

6. Saatvedt K, Lindberg H, Michelsen S, et al. Release of soluble tumor necrosis factor alpha receptors during and after pediatric cardiopulmonary bypass. Correlation with hemodynamic and clinical variables. Cytokine 1996; 8: 944-8.

7. Mann DL, Young JB. Basic mechanisms in congestive heart failure: recognizing the role of proinflammatory cytokines. Chest 1994; 105: 897-904.

8. Billiau A, Vandekerckhove F. Cytokines and their interactions with other inflammatory mediators in the pathogenesis of sepsis and septic shock. Eur J Clin Invest 1991; 21: 559-73.

9. Ungureanu LD, Balligand JL, Kelly RA, Smith TW. Myocardial contractile dysfunction in the systemic inflammatory response syndrome: role of a cytokineinducible nitric oxide synthase in cardiac myocytes. J Mol Coll Cardiol 1995; 27: 155-67.

10. Nosé PS. Cytokines and reperfusion injury. J Card Surg 1993; 8: 305-8.
11. Adams III JE, Abendschein DR, Jaffe AS. Biochemical markers of myocardial injury: is MB creatine kinase the choice for the 1990s? Circulation 1993; 88 750-63.

12. Del Carlo CH, O'Connor CM. Cardiac troponins in congestive heart failure. Am Heart J 1999; 138: 646-53.

13. Antman EM. Medical Management of the Patient Undergoing Cardiac Surgery. In: Braunwald E. Heart Disease, $5^{\text {th }}$ ed. Philadelphia: WB Saunders Company, 1997: $1715-40$

14. Williams G, Giroir BP. Regulation of cytokine gene expression: tumor necrosis factor, interleukin-1, and the emerging biology of cytokine receptors. New Horizons 1995; 3: 276-87.

15. Brauner JB, Rohde LE, Clausell N. Circulating endothelin-1 and tumor necrosis factor-a: early predictors of mortality in patients with septic shock. Int Care Med 2000; 26: 305-13.

16. Wu AHB. Use of cardiac markers as assessed by outcomes analysis. Clin Bioch 1997; 30: 339-50.

17. Polanczyk CA, Lee TH, Cook EF, et al. Cardiac troponin I as a predictor of major cardiac events in emergency department patients with acute chest pain. J Am Coll Cardiol 1998; 32: 8-14

18. Immer FF, Stocker F, Seiler AM, et al. Troponin-I for prediction of early postoperative course after pediatric cardiac surgery. J Am Coll Cardiol 1999; 33: 1719-23.

19. Etievent JP, Chocron S, Toubin G, et al. Use of cardiac troponin I as a marker of perioperative myocardial ischemia. Ann Thorac Surg 1995; 59: 1192-4.

20. Hirsch R, Dent CL, Wood MK, et al. Patterns and potential value of cardiac troponin I elevations after pediatric cardiac operations. Ann Thorac Surg 1998; 65: 1394-9. 